\title{
THE DRY FACTS
}

Drought has wreaked havoc throughout history, destroying crops and causing famine and conflict. And it could be getting worse. By Olive Heffernan.

\section{DEFINING DROUGHT}

Characterized by unusual and persistent dry weather, drought is caused by shifts in global weather patterns such as El Niño, but also increasingly by human-induced climate change.

Identifying drought is difficult, however, so there is considerable uncertainty about whether it is getting any worse.

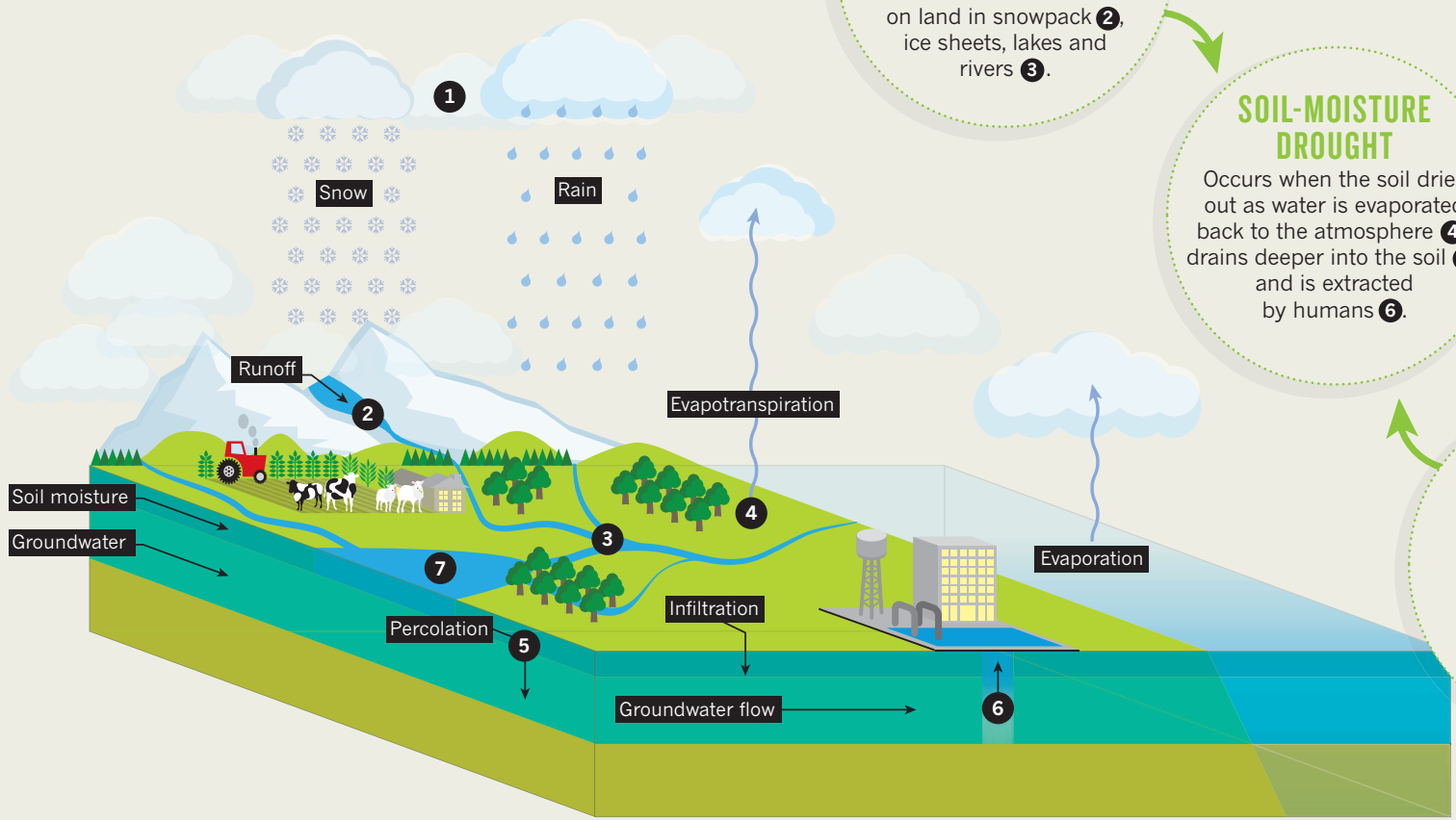

\section{METEOROLOGICAL} DROUGHT

Occurs when a persistent decline in 1 precipitation reduces the water available land in snowpack 2 sheets, lakes and rivers 3

\section{A LONG HISTORY}

Serious droughts have occurred in Australia and Africa, among other regions, in recent decades, but more severe 'megadroughts' have occurred on virtually every continent throughout history.

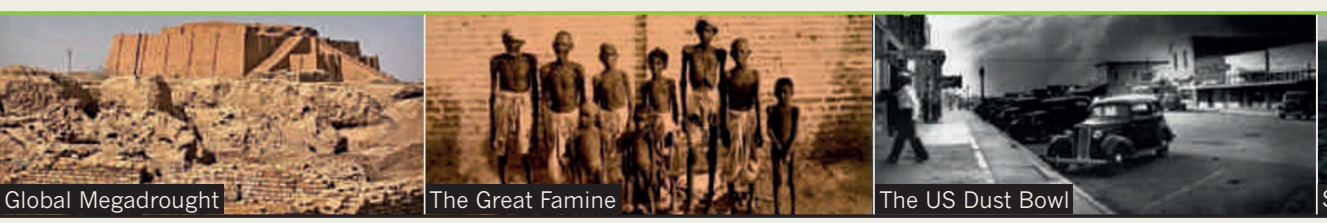

\section{4,200 YEARS AGO} GLOBAL MEGADROUGHT

Where: North America

but spread to Europe,

Africa and Asia. Lasted for several centuries.

Cause: Cooling of the North Atlantic, which reduced rainfall by as much as $30 \%$.

Impact: Linked to demise of Akkadian Empire and civilizations in Greece,

Egypt and the Indus Valley of Pakistan.
1876-78 THE GREAT FAMINE Where: Began in southern India and spread to the tropics and China.

Cause: Severe EI Niño that led to the failure of the Asian monsoon. Food shortages for the poor worsened by Colonial-era imperialism.

Impact: More than

5 million deaths in India and 30 million in total.

\section{1} FEDERATION DROUGHT Where: Australia. It covered half the continent by 1901 . Cause: Lack of rainfall. Impact: Reduced cattle from 12 million to 7 million and sheep from 91 million to 54 million. Led to a massive failure of the wheat crop and caused the Darling River in New South Wales to dry up.
$1930 \mathrm{~s}$

THE US DUST BOWL

Where: Centred on the

Great Plains but covered $60 \%$ of the United States. Lasted all decade.

Cause: Low rainfall and poor land management (deep ploughing).

Impact: Agricultura production fell by $17 \%$. Cost the US government US $\$ 13$ billion in aid and 2.5 million people left the affected states.

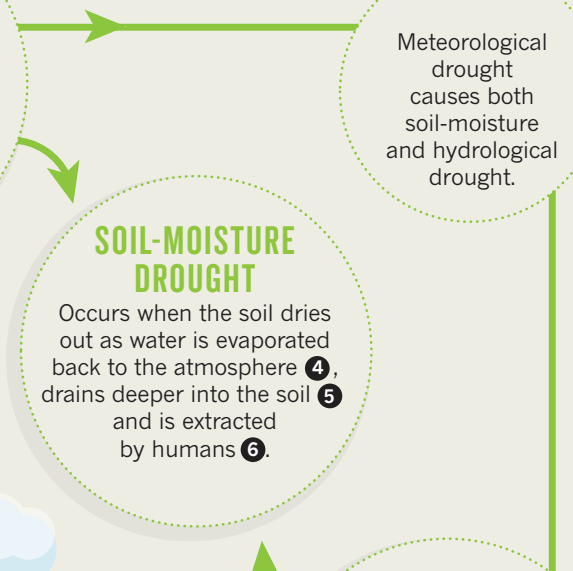

HYDROLOGICAL DROUGHT

Occurs when water reserves in aquifers, lakes and reservoirs 7 fall below average levels owing to high human demand or low rainfall. 


\section{RECENT DROUGHTS}

In 2011 and 2012, drought occurred on almost every continent, partly because of an unusually strong La Niña that caused record rainfall in Australia and led to severe water shortages in Sudan. Hundreds of millions of hectares of crops were destroyed, from wheat in Russia to sugar cane in India. The map shows how rainfall deviated from the norm in this period and highlights the regions most affected by drought many of which are major growing regions for the world's top four staple crops.

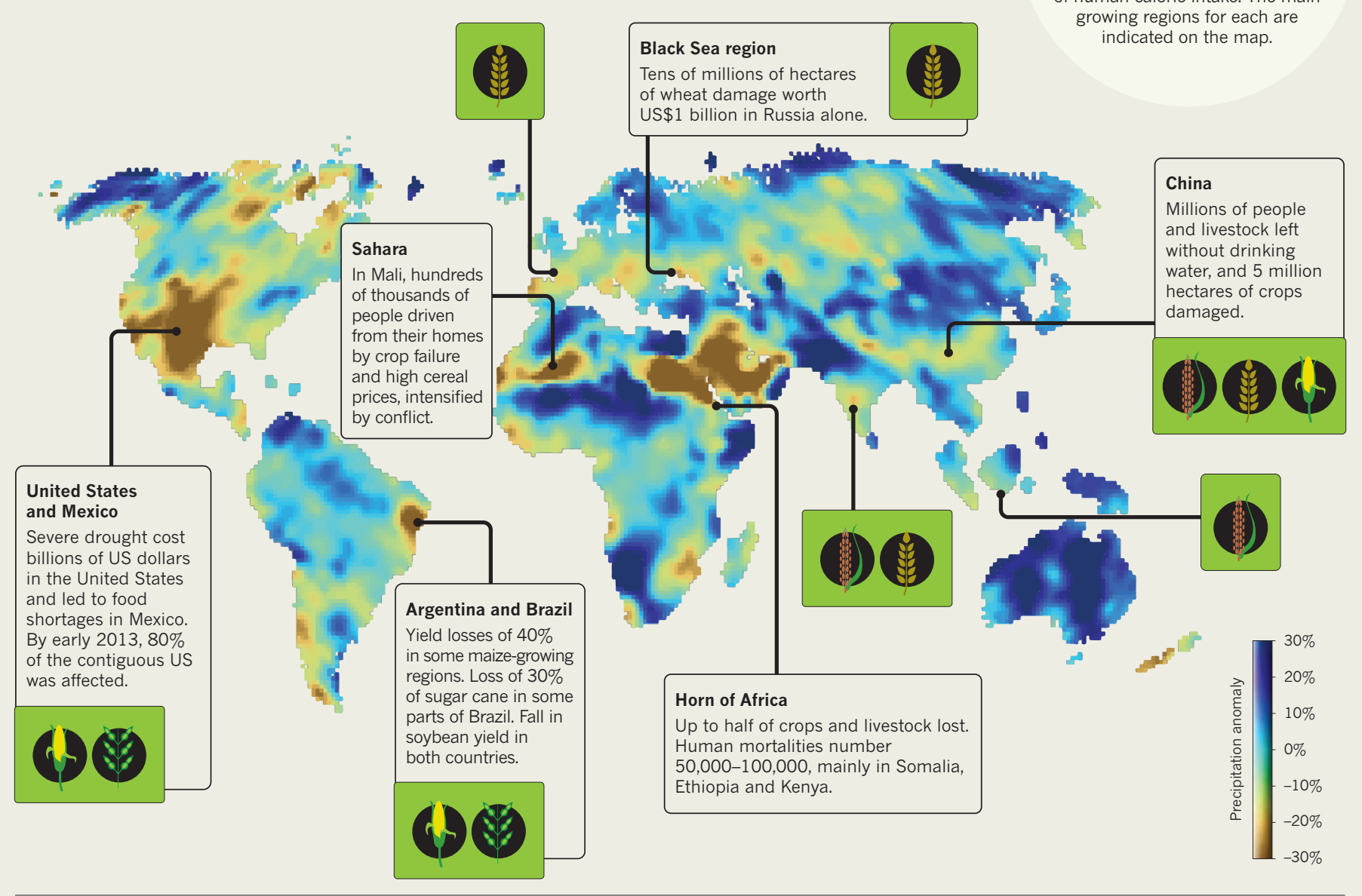

\section{LAND UNDER THREAT}

In many regions, climate change is expected to increase the amount of land at risk from drought and heat, and will threaten more arable areas. Each $1^{\circ} \mathrm{C}$ rise in global warming could cut grain yield by as much as $5 \%$.

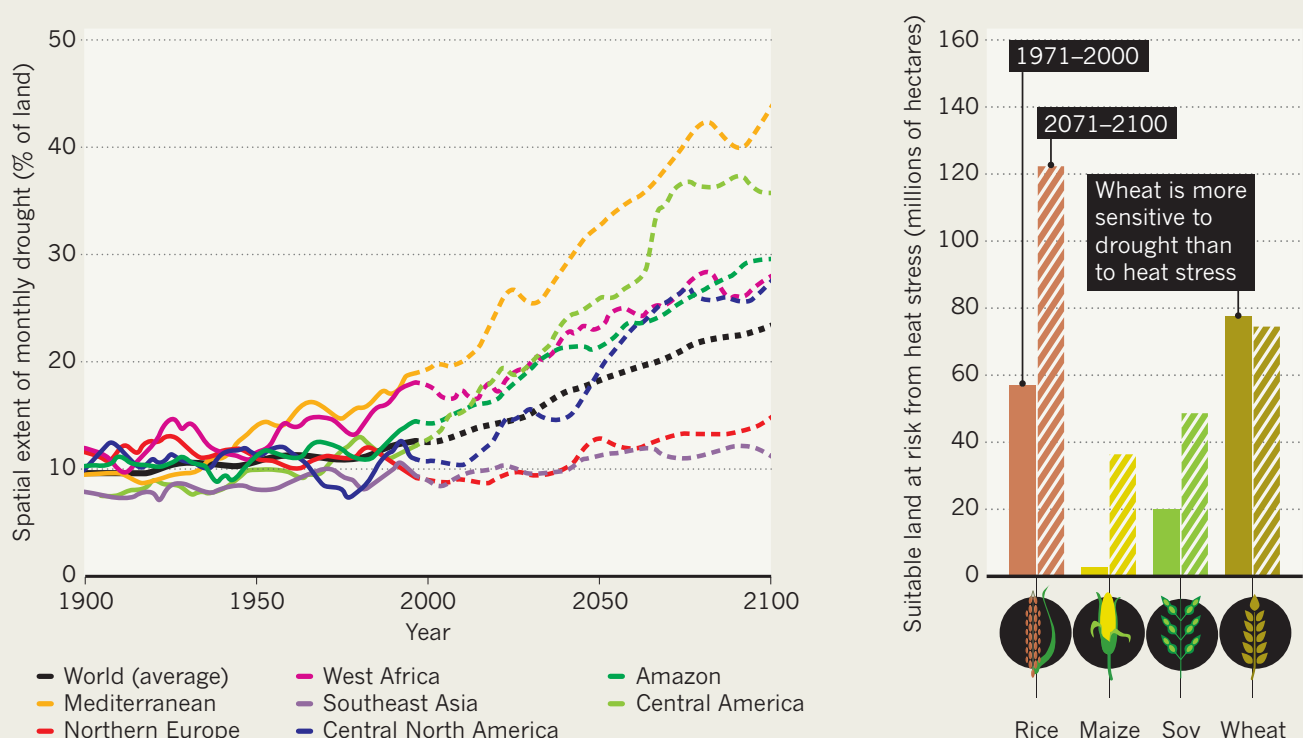

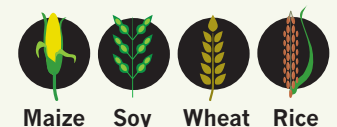

The top four crops account for $45 \%$ of all cultivated land and at least $40 \%$ of human calorie intake. The main rowing regions for each are indicated on the map.

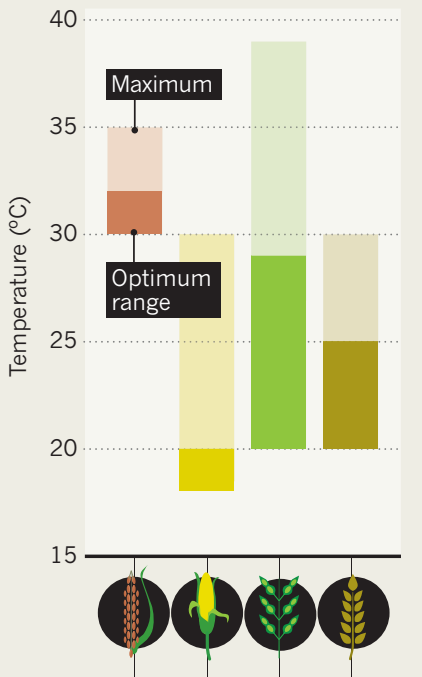

Rice Maize Soy Wheat 